\title{
Synaptic Signaling in Learning and Memory
}

\section{Mary B. Kennedy}

Division of Biology and Biological Engineering, California Institute of Technology, Pasadena, California 91125

Correspondence: kennedym@its.caltech.edu

\section{SUMMARY}

Learning and memory require the formation of new neural networks in the brain. A key mechanism underlying this process is synaptic plasticity at excitatory synapses, which connect neurons into networks. Excitatory synaptic transmission happens when glutamate, the excitatory neurotransmitter, activates receptors on the postsynaptic neuron. Synaptic plasticity is a higher-level process in which the strength of excitatory synapses is altered in response to the pattern of activity at the synapse. It is initiated in the postsynaptic compartment, where the precise pattern of influx of calcium through activated glutamate receptors leads either to the addition of new receptors and enlargement of the synapse (long-term potentiation) or the removal of receptors and shrinkage of the synapse (long-term depression). Calcium/calmodulin-regulated enzymes and small GTPases collaborate to control this highly tuned mechanism.

\section{Outline}

1 Introduction

2 Spine synapses

3 Signaling molecules in spine synapses

4 Regulation of the number of AMPARs in a synapse
5 The role of small GTPases in synaptic plasticity

6 Concluding remarks

References

Editors: Lewis Cantley, Tony Hunter, Richard Sever, and Jeremy Thorner

Additional Perspectives on Signal Transduction available at www.cshperspectives.org 


\section{INTRODUCTION}

The function of the brain is to process and store information about the environment and direct behavior in response to that information. Three major cell types in the brain-excitatory neurons that use glutamate as their transmitter, inhibitory neurons that use $\gamma$-aminobutyric acid (GABA) as their transmitter, and glial cells-work together to respond to the environment while maintaining the overall connectivity among neurons within an acceptable homeostatic range. Excitatory neurons, the most numerous in the brain, each receive thousands of synaptic inputs and, in turn, make thousands of synaptic connections onto other neurons. A human brain contains, on average, 86 billion neurons (Herculano-Houzel 2009) that in toto make trillions of synaptic connections.

A typical cortical excitatory neuron (Fig. 1) comprises a neuronal soma (cell body), several branched dendrites, and a single axon that can extend for many millimeters and often branches to make thousands of individual synaptic connections. The soma is the site of the nucleus and most of the neuron's protein synthetic machinery. Most inhibitory synaptic contacts occur on the somal plasma membrane. In contrast, the highly branched dendrites receive most of the excitatory synaptic contacts, which are made onto small membrane protuberances called dendritic spines (Fig. 1). When the neuronal membrane becomes depolarized to a threshold level, an action potential is initiated at the base of the axon near the soma; this wave of depolarization travels unabated to each of the thousands of presynaptic endings along the axon. Depolarization causes membranous synaptic vesicles within the presynaptic terminals to fuse with the plasma membrane at the "active zone" opposite the postsynaptic site and flood the synaptic cleft with neurotransmitters. Some of the transmitter molecules bind to specific receptors, which are ligand-gated channels in the postsynaptic membrane. Sodium and potassium ions flow through the channels of the activated receptors, decreasing the gradient in their concentration across the membrane and thus producing a localized depolarization called an excitatory postsynaptic potential (EPSP). If the synapse fires repeatedly, or if several different synapses on a neuron fire at the same time, the EPSPs can sum to produce a depolarization that extends to the soma and initiates an action potential.

Information is stored when individual synapses that connect a particular group of neurons become more able (or less able) to generate an action potential in the postsynaptic neuron in response to environmental signals. Memories are stored initially in the hippocampus, where synapses among excitatory neurons begin to form new circuits within seconds of the events to be remembered. An

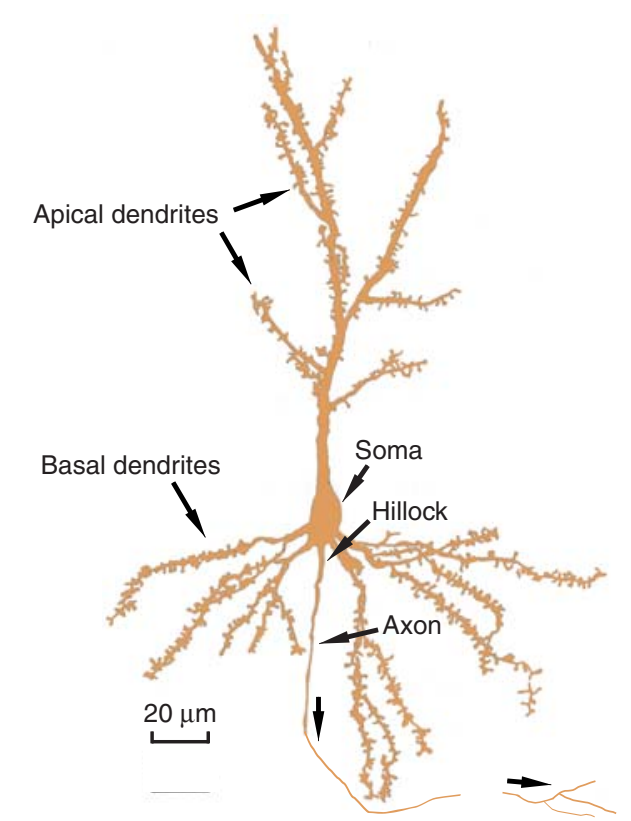

Figure 1. Features of excitatory neurons in the brain. The cell body (soma) of a typical excitatory pyramidal neuron is $\sim 10 \mu \mathrm{m}$ in diameter and is located in one of several sheets of tightly packed somas that define the layers of the neocortex and hippocampus. Apical and basal dendrites extend from the soma, reaching into adjacent areas that are referred to as neuropil. Postsynaptic structures are located in tiny membrane protuberances called spines that can be seen along the dendrites. Each soma gives rise to one axon, which has a smaller diameter than the numerous dendrites. The axon can extend for millimeters from the soma and branches to form thousands of presynaptic terminals where transmitter is released onto the postsynaptic sites of other neurons. The axon hillock is located at the base of the axon. Action potentials are usually initiated at this site; they travel along the axon (arrows) to presynaptic terminals keeping a uniform amplitude of depolarization. Back-propagating action potentials travel in the opposite direction through the soma and into the dendrites. The size of their depolarization decreases as they travel and is regulated by the composition of dendritic ion channels. (From Peters and Kaiserman-Abramof 1970; modified, with permission, (C) Wiley.)

increase in the strength of a relatively small number of synapses can bind connected neurons into a circuit that stores a new memory. A deceptively simple principle guides the direction and amplitude of this synaptic plasticity: neurons that fire together, wire together. When release of transmitter at a synapse is repeatedly correlated with firing of action potentials in the postsynaptic neuron, they become stronger. In contrast, when release of transmitter at a synapse repeatedly fails to correlate with postsynaptic firing, because the resulting EPSPs do not sum to produce the required threshold depolarization, they become gradually weaker and may disappear altogether. Essentially all of the glutamatergic synapses between excitatory neurons in the hippocampus and cortex of the mammalian brain display this behavior. Such synapses are referred to as Hebbian 
synapses, after Donald Hebb, who first suggested a similar principle in 1949. Nonglutamatergic synapses do not display this Hebbian behavior. The unique plasticity of excitatory glutamatergic synapses is an essential mechanism of memory formation. Glutamatergic synaptic plasticity, and thus memory formation, can be modulated by release of the inhibitory transmitter GABA and by the influence of acetylcholine, biogenic amines, small peptides, and larger protein hormones released from neurons and glial cells; but synapses that release these other transmitters do not display Hebbian behavior.

The ongoing pattern of electrical activity through Hebbian synapses influences cellular processes in the postsynaptic neuron at many time scales. In a few seconds, changes can be triggered in the structure of the postsynapse itself. Over minutes, the summation of synaptic activity can result in increased levels of the classical second messengers cAMP and calcium and activation of the MTOR and MAPK pathways (Kennedy et al. 2005), leading to up-regulation of translation of mRNAs stored in the dendritic shaft near active synapses (Ho et al. 2011). Local translation is believed to provide proteins needed for remodeling of synapses and dendrites in response to high synaptic activity. Over a few hours, activity-dependent nuclear transcription factors stored near the synapse can become activated and travel from the synapse into the nucleus (Flavell and Greenberg 2008; Ch'ng and Martin 2011). These changes in dendritic protein synthesis and in nuclear transcription can influence the structure of the neuron and its role in neuronal networks for hours, days, or a lifetime. For example, new ion channels may be transcribed and inserted into the membrane to change the intrinsic electrical firing pattern of the neuron, or the overall production of excitatory receptors may be dampened to maintain homeostatic balance.

Here I focus on the specialized machinery that underlies Hebbian behavior of synapses between excitatory neurons. At this time, signal transduction involved in memory formation is best understood, although still incompletely, for the early phases of plasticity.

\section{SPINE SYNAPSES}

In the brain, most synapses between excitatory neurons are located on spines, tiny compartments that protrude from the neuron's highly branched dendrites (Fig. 2). A typical excitatory pyramidal neuron in the hippocampus or cortex has $\sim 10,000$ such synapses, most spines hosting just a single synapse. Spines vary in size from $\sim 0.5-2 \mu \mathrm{m}$ in length, from $\sim 0.25-1 \mu \mathrm{m}$ in width, and from $\sim 10-100$ attoliters in volume. The synaptic contact itself usually occurs at the tip of the spine. It comprises the presynaptic active zone, the synaptic cleft, and the postsynaptic receptor cluster and varies in diameter from $\sim 0.1$ to $0.8 \mu \mathrm{m}$. Spines also vary in shape from stubby to thin to "mushroom-shaped." In general, the larger, mushroom-shaped spines contain stronger synapses. Functionally, a stronger synapse is defined as one that contributes more depolarization to the neuronal membrane upon activation than a weaker one; thus, its activation is more likely to generate an action potential in the postsynaptic neuron.

The postsynaptic membranes of spine synapses contain two distinct types of ligand-gated channels that are receptors for the neurotransmitter glutamate but are distinguishable by their ability to respond to pharmacological agents. For 2-amino-3-(3-hydroxy-5-methyl-isoxazol4-yl) propanoic acid (AMPA)-type glutamate receptors (AMPARs), binding of glutamate triggers a small, relatively rapid EPSP, resulting from an influx of potassium and sodium ions. AMPA-type receptors produce an EPSP each time glutamate is released at a synapse. The other class, $\mathrm{N}$-methyl-D-aspartate (NMDA)-type glutamate receptors (NMDARs), are evolutionarily related to AMPARs but are more complex; they are responsible for the Hebbian behavior of spine synapses (Mayer et al. 1984; Nowak et al. 1984). As I discuss in detail below, the channel in NMDARs allows passage of calcium ions, as well as potassium and sodium, and opens only if two conditions are met: glutamate is bound and the synaptic membrane is strongly depolarized, as occurs when release of transmitter is correlated with firing of action potentials in the postsynaptic neuron.

Synaptic plasticity is most often studied by recording electrical responses from synapses of the Schaffer-collateral pathway, which connects two different sets of excitatory neurons in the hippocampus (Lüscher and Malenka 2012). Repeated activation of this pathway, and thus its spine synapses, at a frequency between $\sim 10$ and $100 \mathrm{~Hz}$ for a few seconds usually initiates a process referred to as long-term potentiation (LTP), in which the activated synapses increase in size and more effectively depolarize the postsynaptic membrane. In contrast, activation of these synapses at a lower frequency, between $\sim 1$ and $5 \mathrm{~Hz}$, for several minutes usually initiates a process called long-term depression (LTD), in which the activated synapses decrease in size and less effectively depolarize the postsynaptic membrane. The change in strength of the synapses can last for hours to a lifetime, depending on how often the stimulation is repeated.

Intriguingly, although these processes have opposite effects on the strength of the synapse, both are controlled by the influx of calcium caused by activation of NMDARs. Differences in the timing and amount of calcium entry into the spine through NMDARs account for the opposite outcomes after stimulation of synapses in the two different 
M.B. Kennedy
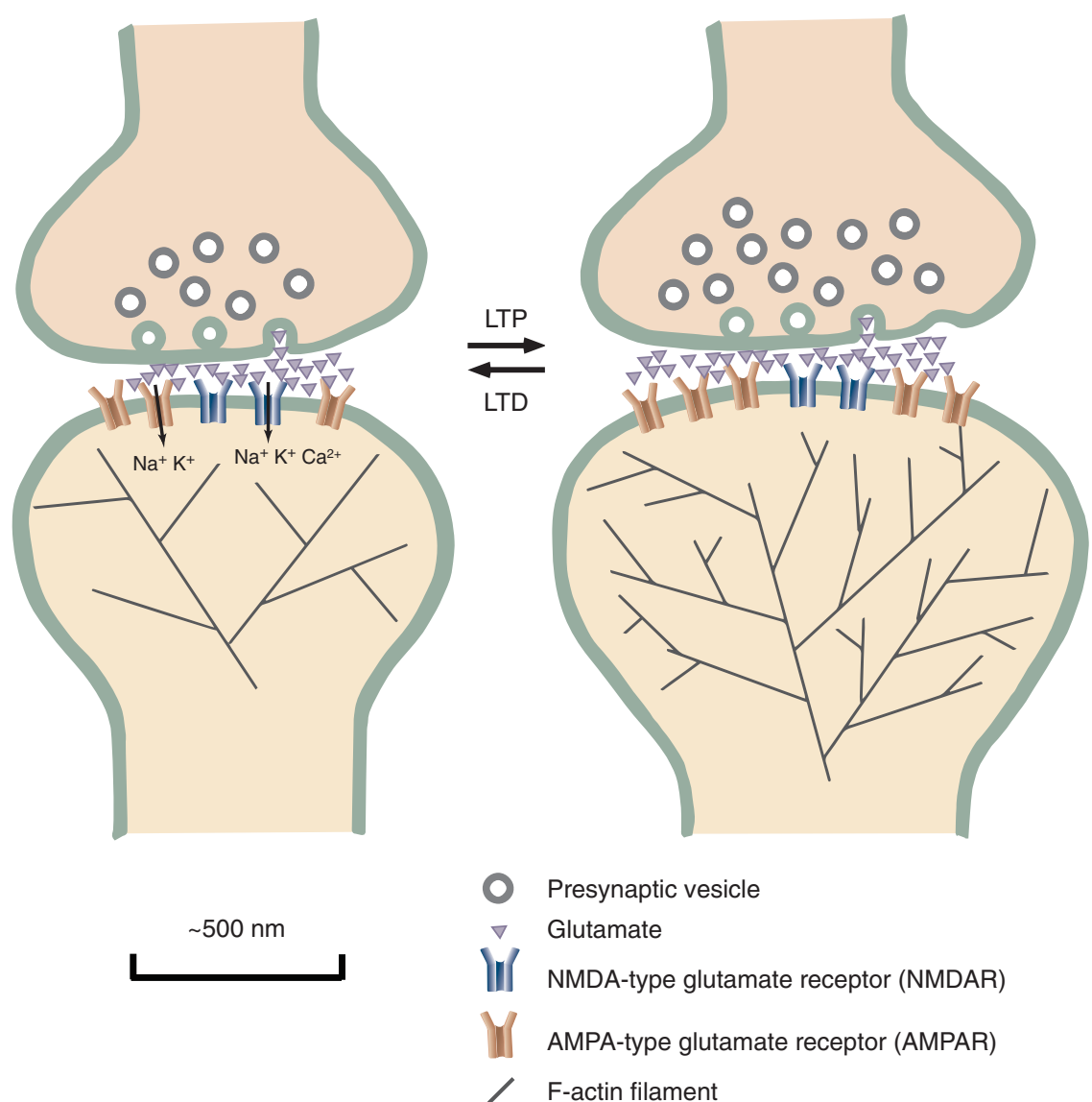

Figure 2. Synaptic plasticity. At the cellular level, one of the most essential elements of memory formation is the adjustment in synaptic strength of excitatory synapses between neurons. AMPA-type glutamate receptors (yellow) allow passage of sodium and potassium through their channel. Their principal function is to depolarize the membrane, producing an excitatory postsynaptic potential (EPSP). NMDA-type glutamate receptors (blue) also depolarize the membrane, but in addition to sodium and potassium, calcium flows through their channel and can initiate synaptic plasticity. A long-lasting increase in synaptic strength is referred to as long-term potentiation (LTP). LTP involves the addition of new synaptic AMPA-type glutamate receptors (AMPARs) and an increase in the size of the head of the postsynaptic spine, supported by an increase in the size and branching of the actin cytoskeleton. Long-term depression (LTD) is a long-lasting decrease in synaptic strength that involves a decrease in the number of synaptic AMPARs and shrinkage of the spine head. LTP is induced when repeated firing of an action potential in the presynaptic terminal and the resulting release of glutamate cause firing of action potentials in the postsynaptic neuron. LTD is induced when repeated firing of an action potential in the presynaptic terminal does not cause firing of action potentials in the postsynaptic neuron.

frequency ranges (Franks and Sejnowski 2002; Sjostrom and Nelson 2002). The higher frequency, larger amplitude influx of calcium leads to two important molecular changes in the spine synapse over the next 15-60 s (Fig. 2). More AMPARs are inserted into the postsynaptic membrane, increasing the size of the EPSP in the spine upon subsequent synaptic activation. At the same time, the actin cytoskeleton, which gives the spine its shape, is remodeled, producing a larger and more branched cytoskeleton that supports a larger spine head. In contrast, lower frequency, lower amplitude, but more prolonged influx of calcium produces the opposite effect on the spine. The number of
AMPARs in the postsynaptic membrane is reduced, resulting in a smaller EPSP upon subsequent activation, and the actin cytoskeleton shrinks, leaving a smaller spine head. We do not yet know precisely how this delicate differential regulation by calcium influx is achieved. However, much has been learned about the molecular machinery that is responsible.

Although NMDARs initiate synaptic plasticity, their numbers are not altered by the processes that alter AMPA receptor numbers during LTP or LTD. A variety of modulatory agents in the brain can adjust the flux of calcium through NMDARs (Salter and Kalia 2004) or the frequency 
range at which the switch between LTP and LTD occurs, a process called metaplasticity (Abraham and Bear 1996; Yang et al. 2012). Homeostatic regulation can lead to slow changes in the steady-state levels of NMDARs and AMPARs; however, these changes are not directly related to storage of memories.

\section{SIGNALING MOLECULES IN SPINE SYNAPSES}

\subsection{The NMDA-Type Glutamate Receptor and the Hebbian Response}

Both AMPARs and NMDARs are homologous tetramers arranged such that a channel is formed by the intersection of their intramembrane domains (Mayer 2006). Binding of glutamate to two sites on the extracellular portion of the receptor opens the channel. However, the similarity between AMPARs and NMDARs ends there. Opening of the AMPAR channel produces the predictable rapid EPSP (Seeburg 1993). In contrast, opening of the NMDAR channel alone is not sufficient to produce depolarization because the mouth of the channel is blocked by a bound magnesium ion, which acts like a cork in a bottle. Ions can flow through the open channel of the NMDAR only if the membrane is sufficiently depolarized to loosen the binding of the magnesium ion and relieve the "magnesium block" (Ascher and Nowak 1988).

One event that can depolarize the spine membrane sufficiently is a "back-propagating action potential," a type of dendritic depolarization that was discovered relatively recently (Spruston et al. 1995; Magee and Johnston 1997; Stuart et al. 1997; Magee et al. 1998). Axonal action potentials are initiated near the neuronal cell body at the base of the axon, where the threshold for triggering an action potential is lowest. They then propagate to synapses at the end of the axon in a nondecremental fashion; that is, the size of the depolarizing wave does not decrease as it moves along the axon. Dendritic action potentials are also believed to begin at the base of the axon, but they are decremental, decreasing in size as they back-propagate from the base of the axon through the cell body and into the dendrites. The size of the back-propagating potential and the length that it travels depend on the configuration of potassium and sodium ion channels in each dendrite. However, the depolarization produced can be sufficient to relieve the magnesium block at spines along the dendrite. Therefore, the coincidence of glutamate binding to receptors at a spine and the arrival of a back-propagating action potential will allow the NMDAR channels to open. Electrophysiologists still debate whether there are additional circumstances associated with firing of the postsynaptic neuron that result in strong local depolarization of dendrites during synaptic activity. Nonetheless, it is clear that when a synapse repeatedly contributes to the triggering of postsynaptic action potentials, NMDARs in that synapse will be powerfully activated.

A second important difference between NMDARs and AMPARs is the mixture of ions that flow through their channels. Most AMPARs only allow passage of sodium and potassium ions, which produces depolarization. In contrast, calcium passes through NMDAR channels along with sodium and potassium (MacDermott et al. 1986) and acts as a second messenger in the spine. NMDARs stay activated for several tens of milliseconds, during which the channel flickers open in short bursts, partly because magnesium bounces in and out of the mouth of the channel and partly because opening and closing of any protein channel is stochastic in nature. As a result, calcium flows into the spine in irregular bursts, for tens of milliseconds, and is rapidly pumped out by calcium-ATPases and sodium/calcium exchangers (see Bootman 2012). Proteins in the spine cytosol that are sensitive to calcium are thus subjected to rapidly fluctuating levels of the ion that may never reach a stable equilibrium as long as the channel is open. In contrast, AMPARs are active for just a few milliseconds and produce only a brief, transient depolarization.

Finally, NMDARs contain very long carboxy-terminal "tails" ( $\sim 60$ residues in length) that extend into the cytosol and help to organize the postsynaptic signaling machinery. In adults, the tetrameric NMDAR is assembled from mixtures of five receptor subunit isoforms: GluN1, GluN2A, GluN2B, GluN2C, and GluN2D (Kutsuwada et al. 1992; Monyer et al. 1992). Each individual receptor contains two GluN1 subunits, which are necessary for formation of the channel, and a pair of GluN2 subunits (Furukawa et al. 2005; Mayer 2006), which contribute the long cytosolic tails. The carboxy-terminal tail of GluN1 is shorter ( $\sim 100-120$ residues) compared with those of the GluN2 subunits. In the hippocampus and cortex, the predominant GluN2 subunits are GluN2A and GluN2B (Monyer et al. 1994). Their 600-residue tails associate with distinct but overlapping sets of signaling enzymes and scaffold proteins (Foster et al. 2010). Both of them can associate with the primary postsynaptic density scaffold protein PSD95 and with calcium-/calmodulin-dependent protein kinase II (CaMKII); however, the affinity of CaMKII for GluN2B is considerably higher than for GluN2A (Gardoni et al. 2001).

\subsection{Calcium-Regulated Signaling Enzymes in the Postsynaptic Density}

The postsynaptic density (PSD) is the name that was given by electron microscopists to a densely staining plaque of proteinaceous material attached to the cytosolic face of the 
postsynaptic membrane opposite presynaptic vesicle release sites at excitatory synapses. Subcellular fractionation and biochemical analyses (see Kennedy 1997) revealed that it contains specialized scaffold proteins that physically link NMDARs, AMPARs, and signaling enzymes responsible for synaptic plasticity (Kennedy 2000; Sheng and Kim 2011).

About eight calcium-sensitive enzymes reside in significant numbers in or near the PSD, although some appear to have a more central role in synaptic plasticity than others (Table 1). CaMKII and the phosphoprotein phosphatase calcineurin (also known as PP2B) are required for NMDAR-dependent induction of LTP and LTD, respectively. The others participate in signaling pathways that can regulate synaptic function in response to modulatory agents, such as acetylcholine, biogenic amines, or neuropeptides.

\subsubsection{CaMKII}

CaMKII makes up $\sim 1 \%$ of total protein in the forebrain and $\sim 2 \%$ in the hippocampus (Bennett et al. 1983; Erondu and Kennedy 1985). These high levels of expression, at least 10 times higher than those of other signaling enzymes, are a specialization of excitatory neurons, which represent most of the mass of the forebrain (Sik et al. 1998). CaMKII is present throughout the cytosol of somas, axons, and dendrites, including spines in which it is present both in the cytosol and the PSD (Kennedy et al. 1983; Chen et al. 2005; Khan et al. 2012). Activation of synaptic NMDARs increases association of CaMKII with spines and the PSD; however, the role and mechanism of this translocation are still incompletely understood (Khan et al. 2012).

CaMKII is a complex holoenzyme, the structure of which has interesting consequences for the dynamics of its activation by calcium/CaM (Fig. 3). Each holoenzyme comprises 12 catalytic subunits held together by their carboxy-terminal association domains (Bennett et al. 1983; Kolb et al. 1998; Rosenberg et al. 2005, 2006). Mammalian

TABLE 1. Calcium-sensitive enzymes in or near the PSD

\section{Calcium/CaM regulated}

Calcium-/calmodulin-dependent protein kinase II (CaMKII)

Calcineurin (also known as protein phosphatase 2B)

Calcium/CaM-stimulated adenylyl cyclase (AC1)

Neuronal nitric oxide synthase (nNOS)

Calcium/CaM-dependent phosphodiesterase (PDE1)

Ras-GRF1/2

Calcium regulated

Protein kinase C (PKC)

Calpain protease

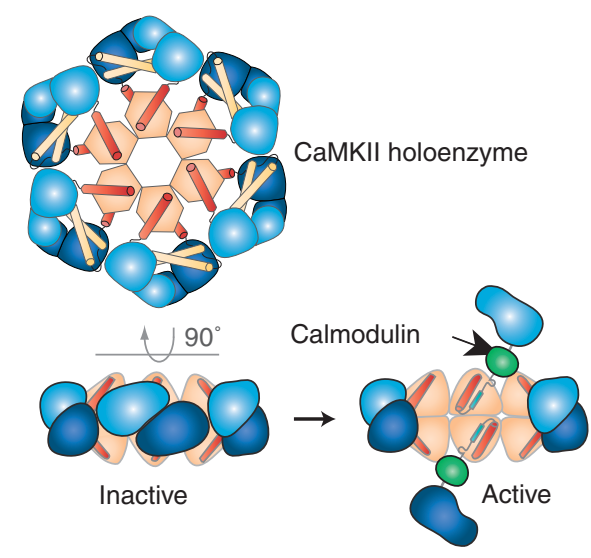

Figure 3. CaMKII. CaMKII is a ring of six dimers of calcium-/calmodulin (CaM)-activated catalytic subunits. The subunits are bound together by a central "hub" structure (light orange) formed from the carboxy-terminal association domains of each subunit. The inactive dimers (light and dark blue) are docked against the central hub by interactions among helices in the association domains (red) and residues in their inhibitory domains (light yellow). Binding of activated calmodulin to the subunit dimers is cooperative because binding to one subunit dissociates the dimer and makes the other subunit more available for calmodulin binding. The activated subunits are mobile and, in addition to phosphorylating other synaptic proteins, they can autophosphorylate each other at a critical threonine residue that locks the subunit in an active state until it is dephosphorylated by phosphatase 1 or phosphatase 2A. (From Rosenberg et al. 2005; modified, with permission, (C) Elsevier.)

genomes encode four highly similar CaMKII subunits: $\alpha$, $\beta, \gamma$, and $\delta$ (Gaertner et al. 2004). They can form stable homo-oligomers or hetero-oligomers that contain differing numbers of each isoform; the numbers depend on their relative rates of synthesis. Their major sequence differences occur in the linker region between the catalytic and association domains. Only the $\alpha$ and $\beta$ subunits are highly expressed in brain; and the $\alpha$ subunit is only expressed in neurons. In forebrain, the $\alpha: \beta$ ratio is $\sim 3: 1$ (Bennett et al. 1983). Thus, the unusually high levels of CaMKII in forebrain are primarily a result of the level of expression of the $\alpha$ subunit.

Atomic structures of holoenzymes from Caenorhabditis elegans (Rosenberg et al. 2005) and human (Rellos et al. 2010; Chao et al. 2011) revealed that the 12 subunits are arranged in two closely apposed rings (Fig. 3). The association domains are located at the center of the ring and the catalytic domains are around the outside. When the enzyme is inactive, each catalytic domain in the upper ring forms a dimer with a corresponding subunit in the lower ring. Binding of calcium-CaM to one of the subunits in a dimer activates that subunit and frees its partner, increasing its availability to bind calcium-CaM. The magnitude of the resulting cooperativity for binding of calcium-CaM depends on the nature of the subunit dimer interface and 
the length of the linker region between the catalytic and association domains (Chao et al. 2010, 2011). Thus, the sensitivity of CaMKII to activation by calcium is highly tuned, differing among different species and among individual isoforms in the same species.

When CaMKII is inactive, an inhibitory domain blocks the substrate-binding site. Upon activation by calciumCaM, CaMKII subunits become autophosphorylated. The first autophosphorylation occurs on a threonine residue (T286) in the inhibitory domain, preventing its binding to the substrate-binding site. The phosphothreonine keeps the active site open even after the calcium concentration returns to baseline and calcium-CaM dissociates (Miller and Kennedy 1986; Miller et al. 1988; Schworer et al. 1988). This first autophosphorylation event is intersubunit; occurring when one activated subunit in the holoenzyme binds to and phosphorylates the inhibitory domain of a neighboring subunit (Hanson et al. 1994). The target subunit must also have bound calcium-CaM so that its inhibitory domain is exposed (Fig. 3) (Hanson et al. 1994; Rellos et al. 2010). Thus, conversion of CaMKII to a calcium-independent state depends on the square of the active CaM concentration. This combined cooperativity of CaM binding and CaM-induced autophosphorylation contributes to the dependence of CaMKII activity on the frequency of calcium influx into the dendritic spine (Chao et al. 2010).

A second autophosphorylation occurs on threonine residues located in the CaM-binding domain (T305 or T306) and blocks binding of calcium-CaM to the kinase (Patton et al. 1990). This event desensitizes CaMKII to subsequent activation by calcium/CaM. Reversal of calcium-independent activity and alleviation of desensitization requires dephosphorylation of the respective sites by protein phosphatase PP1 or PP2A (Shields et al. 1985). Thus, the duration of activation of CaMKII at the postsynaptic site by synaptic activity is regulated reversibly by the magnitude of the transient formation of calcium-CaM during synaptic activity and by local regulation of protein phosphatase activity, which is incompletely understood.

The earliest evidence for a role of CaMKII in synaptic plasticity came from pharmacological experiments in which inhibitors of protein kinases injected postsynaptically blocked induction of LTP (e.g., Malinow et al. 1989). However, definitive evidence for its involvement was obtained when disruptions in learning behavior and synaptic plasticity were observed in a series of mouse mutants. Deletion of the $\alpha$ subunit of CaMKII, for example, results in a deficiency in LTP and impaired spatial learning (Silva et al. 1992a,b). Remarkably, mutation of T286 to alanine in the $\alpha$ subunit abolishes LTP and spatial learning altogether, establishing that autophosphorylation of T286 in CaMKII plays a central role in induction of LTP (Giese et al. 1998).
The concentration of CaMKII in spines and the PSD is highly variable, and regulated by synaptic activity. Estimates of the number of holoenzymes in an average spine (64 attoliters in volume) vary from $\sim 200$ to $\sim 1000$ (Bennett et al. 1983; Erondu and Kennedy 1985; Lee et al. 2009). Estimates of the number of CaMKII holoenzymes in an average PSD are more variable, ranging from $\sim 10$ to $\sim 100$ (Chen et al. 2005; Ding et al. 2013). Synaptic activity has been observed to recruit CaMKII to postsynaptic sites, although the mechanism of this movement is not clear (Shen and Meyer 1999). Once in the spine, CaMKII can attach to several docking sites: F-actin filaments, which bind a site on the $\beta$ subunit (Shen et al. 1998); the cytosolic tails of NR2 subunits of NMDARs (Leonard et al. 2002), which bind a site on both the $\alpha$ and $\beta$ subunits; and a scaffold protein termed densin (Walikonis et al. 2001; Carlisle et al. 2011), which binds specifically to $\alpha$ subunits. The significance and precise dynamics of these regulated movements of the CaMKII holoenzyme remain to be determined.

The spine and PSD contain many potential targets for phosphorylation by CaMKII, including AMPAR subunit GluA1, the neuronal GTPase-activating protein (GAP) synGAP, and AMPAR-associated transmembrane AMPAR regulatory proteins (TARPs) (see below), all of which are important for orchestrating the early stages of synaptic plasticity. However, the precise timing and coordination of phosphorylation events following influx of calcium are unknown.

\subsubsection{Calcineurin}

Calcineurin is a calcium/CaM-activated protein phosphatase found in many cell types. Injection of inhibitors of calcineurin into postsynaptic neurons in hippocampal slices first suggested that its activity is required for induction of LTD (Mulkey et al. 1994). Both brain isoforms of its catalytic subunit (CNA $\alpha$ and $\mathrm{CNA} \beta$ ) bind calcium-CaM and form a heterodimer with the regulatory subunit CNB1, which also binds calcium (Kuno et al. 1992). The requirement of calcineurin for induction of LTD was confirmed in hippocampal slices from mice with a forebrain-specific deletion of CNB1. The magnitude of LTD was reduced in these slices and the frequency threshold for the transition from induction of LTD to induction of LTP was shifted to a lower value (Zeng et al. 2001). These findings led to the hypothesis that the relative activation of CaMKII and calcineurin determines whether LTP or LTD will be induceda hypothesis that remains to be proven. An implication of this hypothesis is that the steady-state number of AMPARs at a synapse and the steady-state size of the actin cytoskeleton are maintained by a balance of CaMKII and 
calcineurin activities. More recent work reveals that the mechanisms controlling the size and strength of the postsynapse involve the action of several signaling enzymes. For example, the broader-specificity protein phosphatases PP1 and PP2A also appear to be necessary for induction of LTP (Mulkey et al. 1993). It is not yet clear how synaptic activity regulates these two phosphatases. Furthermore, protein kinases PKA and PKC, which mediate the action of other major second messenger pathways, can regulate synaptic plasticity when activated by any of several modulatory neurotransmitters, including acetylcholine, biogenic amines, and neuropeptides (Abeliovich et al. 1993; Blitzer et al. 1995; Kennedy et al. 2005).

A possible link between PKA, calcineurin, and PP1 involves a cycle similar to that found in glycogen metabolism in which a small protein inhibitor of PP1 (inhibitor 1) is activated by phosphorylation by PKA and inactivated by dephosphorylation by calcineurin (Huang and Glinsmann 1976; Lisman 1989). However, deletion of inhibitor 1 in the mouse has no effect on LTP in the Schaffer-collateral pathway or in the medial perforant pathway that arises in the entorhinal cortex, but reduces LTP in synapses from the lateral perforant path (Allen et al. 2000). Importantly, the mutation has no effect on performance of spatial learning tasks. Paralogs of inhibitor 1 that regulate PP1 have been identified in the basal ganglia and cerebellum, but none has been found in the hippocampus or cortex. The divergent effects of inhibitor 1 deletion on different synaptic pathways in the hippocampus show that distinct, heterogeneous molecular mechanisms underlie synaptic plasticity both in different dendritic subregions and in different neuronal subtypes. Two other PP1 regulatory proteins, spinophilin and neurabin, can regulate PP1 activity and its association with the actin cytoskeleton. Deletion of spinophilin eliminates LTD induced by low-frequency stimulation of the Schaffer-collateral pathway (Feng et al. 2000). This is consistent with a requirement for PP1 activity but does not shed light on the relationship of calcium influx to PP1 activity during induction of LTD.

Calcineurin is a more selective phosphatase than PP1 or PP2A, requiring upstream motifs, such as LxVP, in its substrates (Grigoriu et al. 2013). Although there is a small amount of overlap in the target sites for CaMKII and calcineurin, many of their target sites do not overlap. Therefore, the shift in phosphorylation status of individual proteins in the spine during and after an influx of calcium is difficult to predict and is still the subject of study.

\subsubsection{Modulatory Calcium-Sensitive Enzymes}

The calcium/CaM-stimulated adenylyl cyclase isoform AC1 (Wang and Storm 2003), the calcium/CaM-activated cyclic nucleotide phosphodiesterase PDE1 (Sharma et al. 2006), the calcium/CaM-regulated neuronal nitric oxide synthase isoform (nNOS) (Salerno et al. 2013), members of a family of calcium-sensitive guanine nucleotide exchange factors (GEFs) called RasGRF1 and RasGRF2 (Feig 2011), calcium-sensitive PKC isoforms (Lipp and Reither 2011), and the calcium-dependent protease calpain (Croall and DeMartino 1991) are all present at low and varying levels in spines and can modulate the sensitivity of a synapse to induction of synaptic plasticity or the magnitude and duration of plastic changes. These modulatory mechanisms are outside our scope here, however.

\subsection{Scaffold Proteins in the PSD}

Signaling enzymes are organized within the PSD by three major classes of scaffold proteins: the PSD95 family (also called MAGUKS [ for membrane-associated guanylate kinases]); the SHANK family (for SH3 domain and ankyrin repeat domain proteins, also called ProSAPs [for prolinerich-synapse-associated proteins]); and the Homer family. Additional scaffold proteins, including A-kinase-anchoring protein (AKAP) 79 (see Newton et al. 2015), neurabin, and spinophilin, serve to position enzymes such as PKA, PKC, calcineurin, and PP1 in the PSD. TARPs, also called stargazins, associate tightly with AMPARs and help to control their trafficking into the synapse (Fig. 4) (Hastie et al. 2013).

PSD95 and its three relatives SAP97, SAP102, and PSD93 are centered $\sim 12-20 \mathrm{~nm}$ from the postsynaptic membrane (Valtschanoff and Weinberg 2001; Chen et al. 2008) and link glutamate receptors to the PSD structure and to proximal signaling enzymes. Each contains three PDZ domains, an SH3 domain, and a carboxy-terminal degenerate guanylate kinase $(\mathrm{GuK})$ domain, all of which act as protein-docking sites (Kornau et al. 1997; Sheng and Kim 2011). The first two PDZ domains of the PSD95 family can bind to several synaptic membrane proteins via PDZbinding motifs in their carboxyl termini, including the GluN subunits of NMDARs, TARPs, and neuroligin, a transmembrane adhesion protein. In adult mammals, PSD95 is the most abundant of the family members and associates preferentially with GluN2A, whereas SAP102 predominates in synapses during the first few weeks of development and associates preferentially with GluN2B (Sans et al. 2000). These two scaffold proteins facilitate the developmental shift from NMDARs that contain predominantly GluN2B to the adult form that contains a mixture of GluN2A and GluN2B (Sans et al. 2000; Elias et al. 2006). The transition is important for synaptic signaling because complexes formed by PSD95 and SAP102 contain different sets of signaling enzymes. 


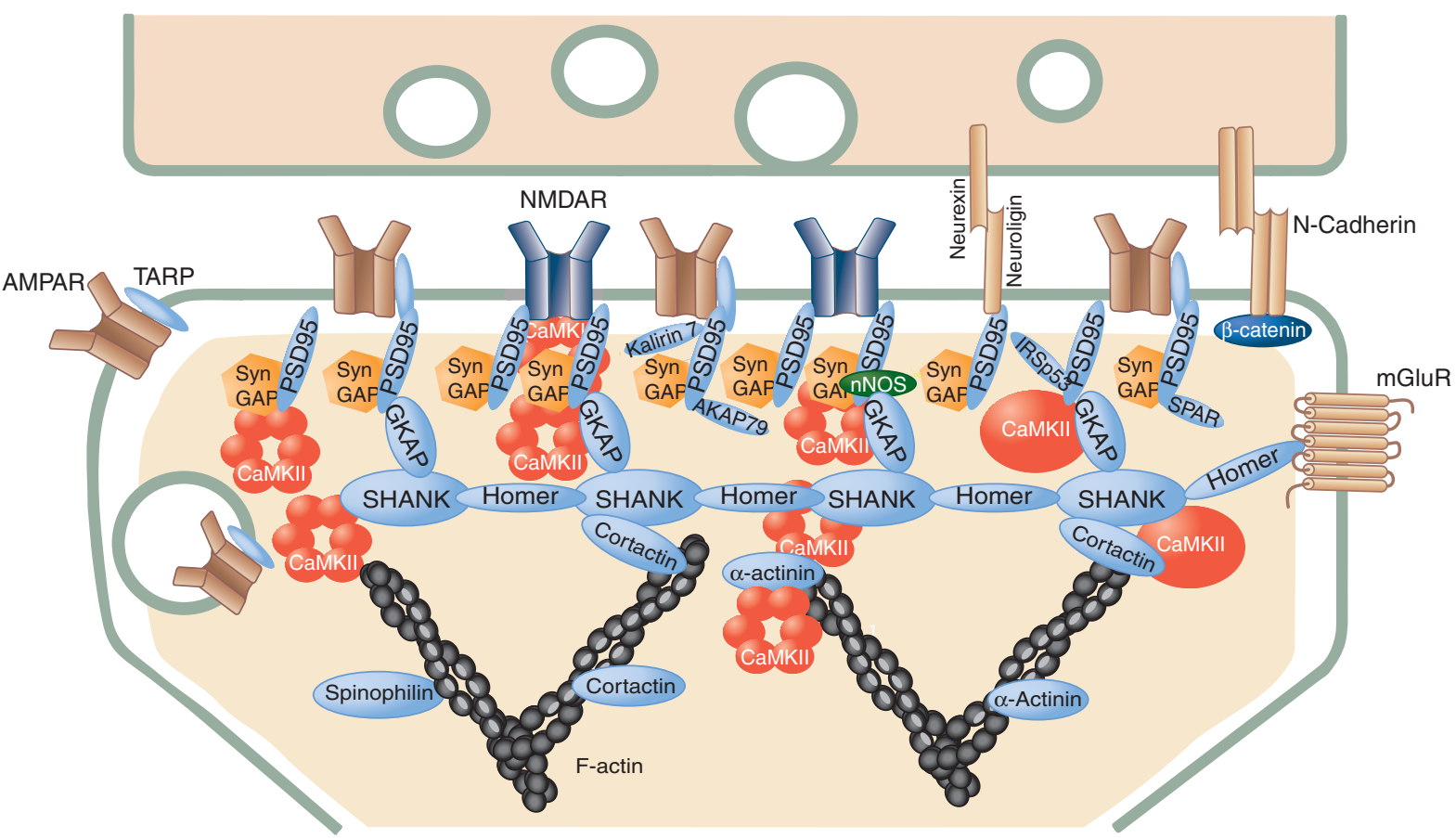

Figure 4. Schematic diagram of the postsynaptic density (PSD) scaffold. NMDARs are immobilized in the postsynaptic membrane by association with PSD95. AMPARs associate with TARPs that bind PSD95. Signaling enzymes are positioned near the receptors by association with PSD95 or other scaffolds. For example, PKA, PKC, and calcineurin bind to AKAP79, which binds to PSD95 and actin in the spine. AMPARs are recruited to the PSD during induction of LTP by diffusional trapping at new docking sites. This diffusional trapping may involve phosphorylation of TARPs by CaMKII, which increases their binding affinity for PSD95. AMPARs are added to or removed from the extrasynaptic plasma membrane pool by exocytosis or endocytosis, respectively. (Modified from Sheng and Kim 2011.)

The PDZ domains can also bind to cytosolic signaling enzymes, including nNOS and synGAP. The carboxy-terminal SH3 domains of the PSD95 family have an unusual split structure created by the insertion of the GuK domain between two $\alpha$ helices (McGee et al. 2001; Tavares et al. 2001). This structure may help regulate oligomerization at the postsynaptic site. The SH3 domain can also bind directly to an AKAP79/150 scaffold protein that localizes PKA, PKC, and calcineurin to the PSD (Gold et al. 2011). Finally, the terminal GuK domain forms a docking site for linker proteins of the GKAP family (for guanylate kinaseassociating protein), providing a critical bridge between the PSD95 family and the next layer of postsynaptic scaffold proteins, the SHANK family (Kim et al. 1997; Takeuchi et al. 1997; Naisbitt et al. 1999).

SHANK proteins act as a "scaffold of scaffolds" within the PSD (Fig. 4) (see Sheng and Kim 2011). They form an interacting network centered $\sim 25 \mathrm{~nm}$ from the postsynaptic membrane and contain multiple, differentially spliced protein-interaction domains (Sheng and Kim 2000; Boeckers et al. 2002). GKAP binds to a PDZ domain in SHANK, linking it to the PSD95 scaffold (Fig. 4). A pro- line-rich domain in SHANK links it to the actin cytoskeleton via the $\mathrm{SH} 3$ domain of cortactin. Cortactin is an F-actin-binding protein that also enhances binding of actin to the ARP2/3 complex, facilitating branching of actin filaments.

A second proline-rich domain in SHANK interacts with the Homer family of scaffold proteins (Fig. 4). Homer proteins form tetramers linked by their carboxy-terminal coiled-coil domains. Each tetramer contains four identical amino-terminal EVH domains that bind to prolinerich sites on three classes of synaptic proteins: SHANK, the cytosolic tails of metabotropic glutamate receptors (mGluRs), and inositol 1,4,5-trisphosphate $\left(\mathrm{IP}_{3}\right)$ receptors $\left(\mathrm{IP}_{3} \mathrm{Rs}\right)$. Thus, the Homer proteins can form a bridge between mGluRs and internal calcium stores located in vesicles of smooth endoplasmic reticulum that contain $\mathrm{IP}_{3} \mathrm{Rs}$. Not all spines contain such stores, but when they are present calcium is released into the cytoplasm when $\mathrm{IP}_{3}$ binds to the $\mathrm{IP}_{3} \mathrm{Rs}$ (Bootman 2012). Finally, the EVH domains link all of the Homer complexes directly to SHANK.

The dense protein network formed by these three families of scaffold proteins is highly dynamic. For example, 
PSD95 exchanges between neighboring spines with a median retention time of $\sim 30-100$ min (Gray et al. 2006). Retention time decreases during sensory deprivation (Gray et al. 2006) and also after synaptic activity (Steiner et al. 2008). The composition and size of PSDs thus appear to be regulated in an ongoing way by neural activity. This dynamic scaffold provides the underlying spatial organization for the signaling events that regulate the strength of the synapse (Fig. 4).

Genome-wide association (GWAS) studies have identified mutations or copy-number variants in PSD scaffolds as risk factors for autism spectrum disorders. In humans and in mice, deletion of SHANK scaffold proteins has been repeatedly linked to autistic behaviors (Durand et al. 2007; Herbert 2011; Peca et al. 2011). Similarly, deletion of PSD95 in mice results in behaviors associated with autism, and two human single-nucleotide polymorphisms in the gene encoding PSD95 are associated with characteristics of William's syndrome, a genetic disorder that includes a highly social personality and cognitive difficulties (Feyder et al. 2010).

\section{REGULATION OF THE NUMBER OF AMPARs IN A SYNAPSE}

One of the two central processes associated with LTP and LTD is regulation of the number of synaptic AMPARs. What is the link between activation of calcium-dependent enzymes and control of the number of AMPARs at a synapse? AMPAR number appears to be regulated at several levels, and we are beginning to unravel some of the signaling pathways involved.

AMPARs are tetramers formed from mixtures of four subunits: GluA1, GluA2, GluA3, and GluA4. In adult forebrain neurons, the most prominent subunit combinations are GluA1-GluA2 (so-called GluA1-2 receptors) and GluA2-GluA3 (so-called GluA2-3 receptors) (Lu et al. 2009). Each subunit can be alternatively spliced to form additional isomers. The tetramer combinations are formed during synthesis in the soma and dendrites, and vesicles containing the receptors are then carried to synaptic sites by constitutive membrane trafficking. One important functional distinction among the isomers is the sequence of the cytoplasmic tail (Malinow and Malenka 2002). GluA1, GluA2L, and GluA4 each have a cytoplasmic tail of $\sim 100$ residues, whereas GluA2 and GluA3 have shorter tails ( $\sim 50-70$ residues). The two types of tails each contain distinct phosphorylation sites and distinct PDZ-domain ligands that govern trafficking of the receptor and movement into the synaptic membrane. GluA1-2 receptors are less abundant in PSDs, but they are the receptors that are added to synapses during induction of LTP (Shi et al. 2001).
They are also the receptors that are removed when recently potentiated synapses undergo activity-dependent LTD. In contrast, GluA2-3 receptors cycle constitutively into and out of the PSD, independently of synaptic activity. The GluA2-3 tetramers gradually replace GluA1-2 tetramers during periods of low activity, while maintaining the total steady-state number of AMPA receptors (Shi et al. 2001).

Experiments in which individually tagged surface AMPARs are tracked in real time have provided evidence for a three-step mechanism of activity-induced movement of GluA1-2 tetramers to the synapse. The steps include: (1) exocytosis of AMPARs at extrasynaptic and perisynaptic sites, (2) lateral diffusion into synapses, and (3) rate-limiting diffusional trapping in the PSD (Opazo and Choquet 2011). In this model, activation of NMDARs initiates two parallel signaling cascades: one that facilitates diffusional trapping of AMPARs in the PSD, and a second that increases AMPAR exocytosis perisynaptically (Fig. 5) (Makino and Malinow 2009; Petrini et al. 2009). Thus, a relatively rapid increase in the number of AMPARs at the synapse (less than a minute) is accomplished by diffusional trapping (Opazo et al. 2010); concurrently, the mobile population of AMPARs in the dendritic and perisynaptic region is replenished by exocytotic delivery of new AMPARs over a period of minutes (Makino and Malinow 2009).

Recent work has clarified the mechanism of diffusional trapping. Opazo et al. (2010) found that, in the absence of recent NMDAR activation, AMPARs on the dendritic surface are highly mobile and exchange rapidly between extrasynaptic and synaptic sites. Under these basal conditions, CaMKII is not highly enriched in the PSD (Ding et al. 2013). Activation of NMDARs causes influx of calcium into the spine, which activates CaMKII and causes it to translocate into the PSD, where it phosphorylates several sites on the cytoplasmic carboxyl terminus of the AMPARassociated TARPs (Tomita et al. 2005). This phosphorylation facilitates binding of the TARPs to PDZ domains on PSD95, and thus restricts diffusion of AMPARs, trapping them in the PSD (Opazo et al. 2010). This diffusional trapping mechanism (see Fig. 5A) may result in the addition of new placeholders (slots) for AMPARs, as suggested by Shi et al. (2001).

New AMPARs are added by exocytosis to the plasma membrane of spines and adjoining dendrites during a period lasting several seconds to a few minutes following induction of LTP (Patterson et al. 2010). The biochemical mechanisms by which activation of NMDARs and subsequent activation of CaMKII lead to increased exocytosis of AMPARs are unknown. One clue is that inhibition of the Ras-ERK1/2 pathway partially blocks the activity-induced increase in exocytosis rate (Patterson et al. 2010). 

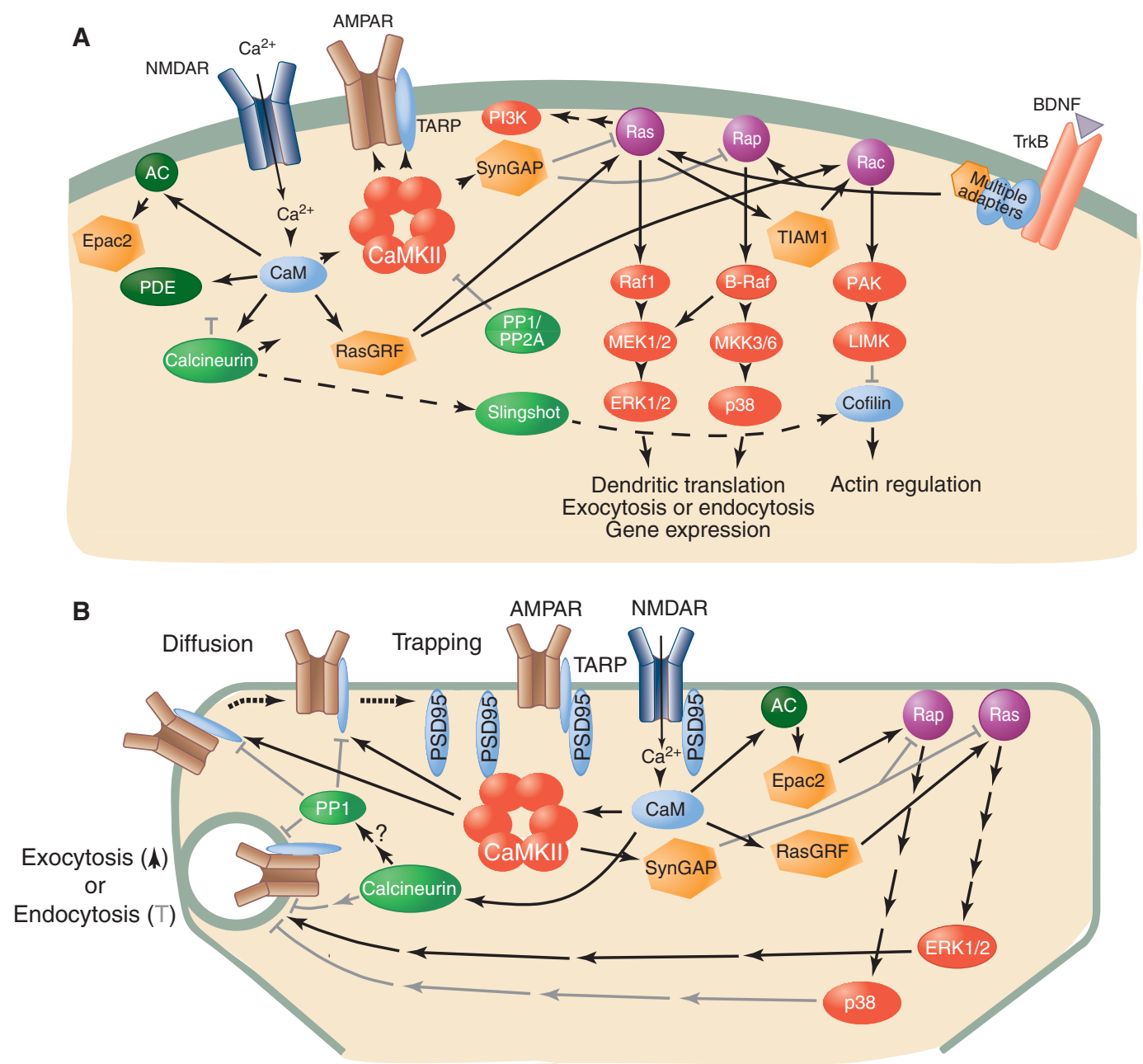

Figure 5. Signaling pathways in the spine. (A) Schematic diagram of major signaling enzymes that mediate changes in synaptic plasticity driven by calcium influx through activated NMDARs. Critical early targets of CaMKII include AMPARs, TARPs, and SynGAP. RasGRF can activate both Ras and Rac. The critical targets of calcineurin are not known. One possibility is the cofilin phosphatase Slingshot, which dephosphorylates and activates the F-actin regulator cofilin. Calcium/CaM-dependent AC and cAMP-phosphodiesterase (PDE) are both present in spines; their responses to calcium could generate a transient spike in cAMP, activating Epac. Ras and Rap regulate trafficking of AMPARs, but their downstream targets, beyond the MAPKs, are not yet known. RasGRF and Ras, acting through the GTPase exchange factor TIAM1 can activate Rac, which regulates pathways that control polymerization of actin. TrkB receptors that respond to the central nervous system (CNS) hormone brain-derived neural factor (BDNF) can provide tonic activation of Ras and Rap. (B) Synaptic regulation of AMPAR trafficking. A critical step in the induction of LTP is the trapping of additional AMPARs in the PSD scaffold through association of TARP and PSD95, which is increased by phosphorylation of residues on TARP by CaMKII. Dephosphorylation of these residues by PP1 can produce loss of AMPARs and depotentiation. Calcineurin, a calcium/CaM-dependent phosphatase, regulates PP1 and endocytosis. Addition of AMPARs to the dendritic plasma membrane by exocytosis, and their removal by endocytosis, occurs at perisynaptic sites in the spine and along the dendritic shaft. Changes in the activity of Ras and Rap are regulated by downstream targets of calcium/CaM, including RasGRF, SynGAP, and adenylyl cyclase (AC). Active Ras and Rap, in turn, activate the MAPKs ERK1/2 and p38. Pathways downstream from ERK facilitate exocytosis, whereas those downstream from p38 facilitate endocytosis. Many of the intermediate steps in the processes downstream from MAPKs are unknown.

\section{THE ROLE OF SMALL GTPases IN SYNAPTIC PLASTICITY}

The Ras and Rho families of small GTPases play important roles in synaptic plasticity, regulating both insertion and removal of AMPARs at the membrane, and growth and shrinkage of the spine actin cytoskeleton (Fig. 5). Their activity influences both homeostatic maintenance of synaptic structure and alterations in structure that occur during changes in synaptic strength. However, most of what we 
know about their roles is still phenomenological; many mechanistic questions remain about how they are activated in the spine by synaptic activity and which downstream targets drive changes in synaptic structure.

Ras and the downstream MAPKK (MEK), which activates the MAPK ERK1/2, appear to be important for activity-driven increases in the number of synaptic AMPARs during induction of LTP (Fig. 5A). Inhibition of MEK before electrophysiological induction of LTP blocks the normal increase in the number of synaptic AMPARs (Zhu et al. 2002). Furthermore, transfections of primary cultures of hippocampal neurons with wild-type, constitutively active, or dominant-negative forms of Ras for $15 \mathrm{~h}$ cause changes in AMPAR-mediated synaptic currents, which is consistent with the notion that endogenous Ras activity contributes to an increase in the number of synaptic AMPARs. Similar experiments with the GTPase Rap suggest that endogenous Rap contributes to a decrease in synaptic AMPAR levels and that inhibition of the downstream MAPK p38 blocks the normal decrease in the number of synaptic AMPARs produced after LTD induction. Because of the relatively long timescale of these experimental manipulations of the Ras and Rap pathways, it has been difficult to separate their effects on homeostatic maintenance of synaptic structure from their roles in acute changes in synaptic strength.

Ras and Rap are activated by several mechanisms in spines (Kennedy et al. 2005). Ras can be activated directly by the calcium/CaM-dependent RasGRF (Feig 2011). A variety of hormones in the brain stimulate receptor tyrosine kinases to activate Ras and Rap. A prominent example in spines is $\operatorname{TrkB}$, which responds to the peptide hormone brain-derived neurotrophic factor (BDNF) and regulates synaptic function in a variety of ways during development and in the adult (Minichiello 2009; Yoshii and ConstantinePaton 2010). Active, phosphorylated TrkB can activate Ras or Rap1, depending on which adapter proteins it binds (York et al. 1998; Stork 2003). In addition, Rap is activated by Epac2, a cAMP-activated Rap GEF (RapGEF), which responds to cAMP formed in the spine by either calcium/ CaM-dependent or G-protein-activated adenylyl cyclases (Grewal et al. 1999; Penzes et al. 2011; Sassone-Corsi 2012).

Downstream Ras effectors in spines include Rafl, which initiates the phosphorylation cascade leading to activation of ERK1/2; phosphoinositide 3-kinase (PI3K), an enzyme that forms $3^{\prime}$ phosphorylated phosphatidylinositol lipids such as $\mathrm{PIP}_{3}$, an activator of several membrane-bound signaling proteins (Hemmings and Restuccia 2012); and TIAM1, a membrane-associated RacGEF (Tolias et al. 2005) that links activation of Ras to activation of Rac. The principal Rap effector in spines is B-Raf, a form of Raf that, in neurons, can activate the p38 MAPK cascade as well as the ERK1/2 cascade (Shi et al. 2005).
A second line of evidence for critical roles of Ras and Rap in regulation of synaptic plasticity comes from studies of synGAP (Chen et al. 1998; Kim et al. 1998). SynGAP is abundant in the PSD and its GAP activity against both Ras and Rap is increased by phosphorylation by CaMKII (Oh et al. 2002, 2004; Krapivinsky et al. 2004). Thus, activation of CaMKII by NMDARs produces a decrease in levels of active Ras. However, this occurs with a delay, and because of the presence of calcium/CaM-sensitive RasGRF in the spine, there is first a transient spike in the level of active Ras (Carlisle et al. 2008). Mice lacking synGAP entirely die shortly after birth (Kim et al. 2003; Vazquez et al. 2004). However, mice heterozygous for synGAP survive and exhibit defects in dendritic spine development, a reduced amplitude of hippocampal LTP, and defective learning behavior (Komiyama et al. 2002; Kim et al. 2003; Vazquez et al. 2004; Carlisle et al. 2008). Thus, synGAP is unusual among PSD proteins in that it exhibits a gene-dosage effect; simply reducing the amount of synGAP by half produces a striking phenotype. The importance of synGAP for cognition is underscored by reports that copy-number variants or single point mutations in the gene encoding it are found in $\sim 5 \%$ of human patients with nonsyndromic intellectual disability (NSID) and none are found in controls (Hamdan et al. 2009, 2011).

Phenotypes of cultured synGAP $P^{-/-}$neurons and syn $G A P^{+/-}$heterozygous mice highlight the role of Ras and Rap in modification of the spine actin cytoskeleton. Cultured syn $G A P^{-/-}$hippocampal neurons show accelerated spine development, and at maturity their spines are significantly larger than those of wild type (Vazquez et al. 2004). Neurons in intact brains of syn $G A P^{+/-}$heterozygotes also have larger spines, display markedly increased activation of Ras and Rac, and increased phosphorylation of cofilin, a regulator of actin polymerization (Carlisle et al. 2008). In neurons cultured from wild-type mice, activation of NMDARs causes transient dephosphorylation of cofilin, most likely by the specific phosphatase Slingshot, which is activated by calcineurin (Carlisle et al. 2008). The dephosphorylation activates cofilin, leading to depolymerization of actin. Subsequent activation of the kinase PAK leads to phosphorylation and activation of LIM kinase, which then phosphorylates and inactivates cofilin, so that the actin cytoskeleton can repolymerize in a new form. In $s y n G A P^{-/-}$ neurons, the basal level of active PAK is elevated, and the initial transient dephosphorylation of cofilin is blunted (Carlisle et al. 2008), apparently tipping the balance toward increasing actin polymerization and larger spines.

SynGAP ${ }^{-/-}$neurons also have increased levels of synaptic AMPARs (Vazquez et al. 2004; Rumbaugh et al. 2006) and alterations in the regulation of ERK1/2 and p38 (Krapivinsky et al. 2004; Rumbaugh et al. 2006; Carlisle et al. 
2008). Thus, it appears that synGAP exerts a carefully balanced restrictive effect both on spine size and on synaptic strength through its regulation of Ras and Rap activity.

The precise timing of activation of Ras and Rap by their various effectors during induction of LTP or LTD has not been studied with precision; thus, we do not yet know the exact mechanisms by which their activation is coordinated to control transient changes during synaptic plasticity versus homeostatic regulation of neuronal excitability.

\section{CONCLUDING REMARKS}

Synapses in the brain release a number of different neurotransmitters including GABA, acetylcholine, the biogenic amines serotonin, dopamine, and norepinephrine, and a wide variety of peptide neurohormones. However, as far as we now know, it is only excitatory glutamatergic synapses that display the Hebbian form of regulation discussed here. The sculpting of excitatory connections in response to input from the environment is the principal mechanism of memory formation in the brain. As excitatory connections are altered by the Hebbian mechanism, new neural networks are formed, and others are weakened or strengthened. All of the other types of synapses contribute to regulation of Hebbian plasticity and help to determine the conditions under which specific memories are formed, as well as how long the memories will last. We know much less about regulation of the size of the signal and response in these other synaptic types, which are fewer in number and are dispersed among the more abundant glutamatergic synapses, making them less accessible to molecular manipulation or measurement.

Another obstacle to our full understanding of synaptic regulation is the subtle variation in mechanisms of synaptic plasticity in spines of different excitatory neuronal types and among neurons in different brain regions. These differences effectively obscure our vision because most experimental methods either sample blindly from the mixture of synapses in a preparation or record average changes from a poorly understood mixture of synaptic types. As we learn which receptors and enzymes play critical roles in modulating synaptic plasticity, new anatomical techniques such as array tomography (Micheva et al. 2010) and superresolution confocal microscopy (Dani et al. 2010) will help to sort out distinct synaptic types.

A final experimental frontier concerns the delicate timing of synaptic regulation required for healthy brain function. To paraphrase Marc Kirschner describing regulation of embryonic development, "In the regulation of the brain, as in the theater, timing is everything. Imagine if, one night, the actors in a play were to miss every single cue, delivering each line perfectly, but always too early or too late. The evening would be a disaster. The same is true in brain function. Starting at the moment when the environment stimulates sensory endings, neurons in the brain send signals to each other to coordinate sensory perception, emotional and motor responses, and the laying down of memories. Not only do the signals have to be correct, they also must be perfectly timed. Otherwise, disasters like mental illness can result" ( paraphrased words in italics) (see kirschner.med.harvard. edu).

A challenge arises from the fact that the biochemical reactions that initiate and sculpt changes in spine structure underlying activity-dependent synaptic plasticity occur in a tiny compartment that contains tens to several hundred copies of the requisite enzymes and effectors. Some of these are immobilized by scaffold proteins that hold them in close proximity to the most important downstream targets. Additional complexity arises from the fact that the initiating calcium signal is always fluctuating, driven by the stuttering kinetics of the NMDAR channel and active calcium pumps in the spine membrane. Thus, time-resolved, highresolution mass spectroscopy and engineered biochemical real-time sensors, in concert with modeling methods such as those afforded by the spatially accurate, stochastic modeling program MCell (e.g., see Kennedy et al. 2005), will be needed to help resolve rapid, transient molecular events involved in memory formation from those underlying homeostatic mechanisms.

\section{REFERENCES}

* Reference is also in this collection.

Abeliovich A, Chen C, Goda Y, Silva AJ, Stevens CF, Tonegawa S. 1993. Modified hippocampal long-term potentiation in $\mathrm{PKC} \gamma$-mutant mice. Cell 75: 1253-1262.

Abraham WC, Bear MF. 1996. Metaplasticity: The plasticity of synaptic plasticity. Trends Neurosci 19: 126-130.

Allen PB, Hvalby O, Jensen V, Errington ML, Ramsay M, Chaudhry FA, Bliss TV, Storm-Mathisen J, Morris RG, Andersen P, et al. 2000. Protein phosphatase-1 regulation in the induction of long-term potentiation: Heterogeneous molecular mechanisms. J Neurosci 20: $3537-$ 3543.

Ascher P, Nowak L. 1988. The role of divalent cations in the N-methyl-Daspartate responses of mouse central neurones in culture. J Physio 399: $247-266$.

Bennett MK, Erondu NE, Kennedy MB. 1983. Purification and characterization of a calmodulin-dependent protein kinase that is highly concentrated in brain. J Biol Chem 258: 12735-12744.

Blitzer RD, Wong T, Nouranifar R, Iyengar R, Landau EM. 1995. Postsynaptic cAMP pathway gates early LTP in hippocampal CA1 region. Neuron 15: 1403-1414.

Boeckers TM, Bockmann J, Kreutz MR, Gundelfinger ED. 2002. ProSAP/ Shank proteins - a family of higher order organizing molecules of the postsynaptic density with an emerging role in human neurological disease. J Neurochem 81: 903-910.

* Bootman MD. 2012. Calcium signaling. Cold Spring Harb Perspect Biol 4: a011171. 
Carlisle HJ, Manzerra P, Marcora E, Kennedy MB. 2008. SynGAP regulates steady-state and activity-dependent phosphorylation of cofilin. J Neurosci 28: 13673-13683.

Carlisle HJ, Luong TN, Medina-Marino A, Schenker LT, Khorosheva EM, Indersmitten T, Gunapala KM, Steele AD, O'Dell TJ, Patterson PH, et al. 2011. Deletion of densin-180 results in abnormal behaviors associated with mental illness and reduces mGluR5 and DISC1 in the postsynaptic density fraction. J Neurosci 31: 16194-16207.

Chao LH, Pellicena P, Deindl S, Barclay LA, Schulman H, Kuriyan J. 2010. Intersubunit capture of regulatory segments is a component of cooperative CaMKII activation. Nat Struct Mol Biol 17: 264-272.

Chao LH, Stratton MM, Lee IH, Rosenberg OS, Levitz J, Mandell DJ, Kortemme T, Groves JT, Schulman H, Kuriyan J. 2011. A mechanism for tunable autoinhibition in the structure of a human $\mathrm{Ca}^{2+} /$ calmodulin-dependent kinase II holoenzyme. Cell 146: 732-745.

Chen H-J, Rojas-Soto M, Oguni A, Kennedy MB. 1998. A synaptic RasGTPase activating protein ( 135 SynGAP) inhibited by CaM Kinase II. Neuron 20: 895-904.

Chen X, Vinade L, Leapman RD, Petersen JD, Nakagawa T, Phillips TM, Sheng M, Reese TS. 2005. Mass of the postsynaptic density and enumeration of three key molecules. Proc Natl Acad Sci 102: 1155111556.

Chen X, Winters C, Azzam R, Li X, Galbraith JA, Leapman RD, Reese TS. 2008. Organization of the core structure of the postsynaptic density. Proc Natl Acad Sci 105: 4453-4458.

Ch'ng TH, Martin KC. 2011. Synapse-to-nucleus signaling. Curr Opin Neurobiol 21: 345-352.

Croall DE, DeMartino GN. 1991. Calcium-activated neutral protease (calpain) system: Structure, function, and regulation. Physiol Rev 71: 813-847.

Dani A, Huang B, Bergan J, Dulac C, Zhuang X. 2010. Superresolution imaging of chemical synapses in the brain. Neuron 68: 843-856.

Ding J-D, Kennedy MB, Weinberg R. 2013. Subcellular organization of CaMKII in rat hippocampal pyramidal neurons. J Comp Neurol 521: 3570-3583.

Durand CM, Betancur C, Boeckers TM, Bockmann J, Chaste P, Fauchereau F, Nygren G, Rastam M, Gillberg IC, Anckarsater H, et al. 2007. Mutations in the gene encoding the synaptic scaffolding protein SHANK3 are associated with autism spectrum disorders. Nat Genet 39: $25-27$.

Elias GM, Funke L, Stein V, Grant SG, Bredt DS, Nicoll RA. 2006. Synapse-specific and developmentally regulated targeting of AMPA receptors by a family of MAGUK scaffolding proteins. Neuron 52: 307-320.

Erondu NE, Kennedy MB. 1985. Regional distribution of type II Ca ${ }^{2+} /$ calmodulin-dependent protein kinase in rat brain. J Neurosci 5: 32703277.

Feig LA. 2011. Regulation of neuronal function by Ras-GRF exchange factors. Genes Cancer 2: 306-319.

Feng J, Yan Z, Ferreira A, Tomizawa K, Liauw JA, Zhuo M, Allen PB, Ouimet CC, Greengard P. 2000. Spinophilin regulates the formation and function of dendritic spines. Proc Natl Acad Sci 97: 9287-9292.

Feyder M, Karlsson RM, Mathur P, Lyman M, Bock R, Momenan R, Munasinghe J, Scattoni ML, Ihne J, Camp M, et al. 2010. Association of mouse Dlg4 (PSD-95) gene deletion and human DLG4 gene variation with phenotypes relevant to autism spectrum disorders and Williams' syndrome. Am J Psychiatry 167: 1508-1517.

Flavell SW, Greenberg ME. 2008. Signaling mechanisms linking neuronal activity to gene expression and plasticity of the nervous system. Annu Rev Neurosci 31: 563-590.

Foster KA, McLaughlin N, Edbauer D, Phillips M, Bolton A, Constantine-Paton M, Sheng M. 2010. Distinct roles of NR2A and NR2B cytoplasmic tails in long-term potentiation. J Neurosci 30: 2676-2685.

Franks KM, Sejnowski TJ. 2002. Complexity of calcium signaling in synaptic spines. Bioessays 24: 1130-1144.

Furukawa H, Singh SK, Mancusso R, Gouaux E. 2005. Subunit arrangement and function in NMDA receptors. Nature 438: 185-192.
Gaertner TR, Kolodziej SJ, Wang D, Kobayashi R, Koomen JM, Stoops JK, Waxham MN. 2004. Comparative analyses of the three-dimensional structures and enzymatic properties of the $\alpha, \beta, \gamma$ and $\delta$ isoforms of $\mathrm{Ca}^{2+}$-calmodulin-dependent protein kinase II. J Biol Chem 279: 12484-12494.

Gardoni F, Schrama LH, Kamal A, Gispen WH, Cattabeni F, Di Luca M. 2001. Hippocampal synaptic plasticity involves competition between $\mathrm{Ca}^{2+} /$ calmodulin-dependent protein kinase II and postsynaptic density 95 for binding to the NR2A subunit of the NMDA receptor. J Neurosci 21: 1501-1509.

Giese KP, Fedorov NB, Filipkowski RK, Silva AJ. 1998. Autophosphorylation at Thr286 of the $\alpha$ calcium-calmodulin kinase II in LTP and learning. Science 279: 870-873.

Gold MG, Stengel F, Nygren PJ, Weisbrod CR, Bruce JE, Robinson CV, Barford D, Scott JD. 2011. Architecture and dynamics of an A-kinase anchoring protein 79 (AKAP79) signaling complex. Proc Natl Acad Sci 108: $6426-6431$.

Gray NW, Weimer RM, Bureau I, Svoboda K. 2006. Rapid redistribution of synaptic PSD-95 in the neocortex in vivo. PLoS Biol 4: e370.

Grewal SS, York RD, Stork PJ. 1999. Extracellular-signal-regulated kinase signalling in neurons. Curr Opin Neurobiol 9: 544-553.

Grigoriu S, Bond R, Cossio P, Chen JA, Ly N, Hummer G, Page R, Cyert MS, Peti W. 2013. The molecular mechanism of substrate engagement and immunosuppressant inhibition of calcineurin. PLoS Biol 11: e1001492.

Hamdan FF, Gauthier J, Spiegelman D, Noreau A, Yang Y, Pellerin S, Dobrzeniecka S, Cote M, Perreau-Linck E, Carmant L, et al. 2009. Mutations in SYNGAP1 in autosomal nonsyndromic mental retardation. N Engl J Med 360: 599-605.

Hamdan FF, Daoud H, Piton A, Gauthier J, Dobrzeniecka S, Krebs MO, Joober R, Lacaille JC, Nadeau A, Milunsky JM, et al. 2011. De novo SYNGAP1 mutations in nonsyndromic intellectual disability and autism. Biol Psychiatry 69: 898-901.

Hanson PI, Meyer T, Stryer L, Schulman H. 1994. Dual role of calmodulin in autophosphorylation of multifunctional CaM kinase may underlie decoding of calcium signals. Neuron 12: 943-956.

Hastie P, Ulbrich MH, Wang HL, Arant RJ, Lau AG, Zhang Z, Isacoff EY, Chen L. 2013. AMPA receptor/TARP stoichiometry visualized by single-molecule subunit counting. Proc Natl Acad Sci 110: 5163-5168.

* Hemmings BA, Restuccia DF. 2012. PI3K-PKB/Akt pathway. Cold Spring Harb Perspect Biol 4: a011189.

Herbert MR. 2011. SHANK3, the synapse, and autism. N Engl J Med 365: $173-175$.

Herculano-Houzel S. 2009. The human brain in numbers: A linearly scaled-up primate brain. Front Hum Neurosci 3: 31.

Ho VM, Lee JA, Martin KC. 2011. The cell biology of synaptic plasticity. Science 334: 623-628.

Huang FL, Glinsmann WH. 1976. Separation and characterization of two phosphorylase phosphatase inhibitors from rabbit skeletal muscle. Eur J Biochem 70: 419-426.

Kennedy MB. 1997. The postsynaptic density at glutamatergic synapses. Trends Neurosci 20: 264-268.

Kennedy MB. 2000. Signal-processing machines at the postsynaptic density. Science 290: 750-754.

Kennedy MB, Bennett MK, Erondu NE. 1983. Biochemical and immunochemical evidence that the "major postsynaptic density protein" is a subunit of a calmodulin-dependent protein kinase. Proc Natl Acad Sci 80: $7357-7361$.

Kennedy MB, Beale HC, Carlisle HJ, Washburn LR. 2005. Integration of biochemical signalling in spines. Nat Rev Neurosci 6: 423-434.

Khan S, Reese TS, Rajpoot N, Shabbir A. 2012. Spatiotemporal maps of CaMKII in dendritic spines. J Comput Neurosci 33: 123-139.

Kim E, Naisbitt S, Hsueh YP, Rao A, Rothschild A, Craig AM, Sheng M. 1997. GKAP, a novel synaptic protein that interacts with the guanylate kinase-like domain of the PSD-95/SAP90 family of channel clustering molecules. J Cell Biol 136: 669-678. 
Kim JH, Liao D, Lau L-F, Huganir RL. 1998. SynGAP: A synaptic RasGAP that associates with the PSD-95/SAP90 protein family. Neuron 20: 683-691.

Kim JH, Lee HK, Takamiya K, Huganir RL. 2003. The role of synaptic GTPase-activating protein in neuronal development and synaptic plasticity. J Neurosci 23: 1119-1124.

Kolb SJ, Hudmon A, Ginsberg TR, Waxham MN. 1998. Identification of domains essential for the assembly of calcium/calmodulin-dependent protein kinase II holoenzymes. J Biol Chem 273: 31555-31564.

Komiyama NH, Watabe AM, Carlisle HJ, Porter K, Charlesworth P, Monti J, Strathdee DJ, O'Carroll CM, Martin SJ, Morris RG, et al. 2002. SynGAP regulates ERK/MAPK signaling, synaptic plasticity, and learning in the complex with postsynaptic density 95 and NMDA receptor. J Neurosci 22: 9721-9732.

Kornau H-C, Seeburg PH, Kennedy MB. 1997. Interaction of ion channels and receptors with PDZ domain proteins. Curr Opin Neurobiol 7: 368-373.

Krapivinsky G, Medina I, Krapivinsky L, Gapon S, Clapham DE. 2004. SynGAP-MUPP1-CaMKII synaptic complexes regulate p38 MAP kinase activity and NMDA receptor-dependent synaptic AMPA receptor potentiation. Neuron 43: 563-574.

Kuno T, Mukai H, Ito A, Chang CD, Kishima K, Saito N, Tanaka C. 1992. Distinct cellular expression of calcineurin $\mathrm{A} \alpha$ and $\mathrm{A} \beta$ in rat brain. $J$ Neurochem 58: 1643-1651.

Kutsuwada T, Kashiwabuchi N, Mori H, Sakimura K, Kushiya E, Kazuaki A, Meguro H, Masaki H, Kumanishi T, Arakawa M, et al. 1992. Molecular diversity of the NMDA receptor channel. Nature 358: 36-41.

Lee SJ, Escobedo-Lozoya Y, Szatmari EM, Yasuda R. 2009. Activation of CaMKII in single dendritic spines during long-term potentiation. Nature 458: 299-304.

Leonard AS, Bayer KU, Merrill MA, Lim IA, Shea MA, Schulman H, Hell JW. 2002. Regulation of calcium/calmodulin-dependent protein kinase II docking to $\mathrm{N}$-methyl-D-aspartate receptors by calcium/calmodulin and $\alpha$-actinin. J Biol Chem 277: 48441-48448.

Lipp P, Reither G. 2011. Protein kinase C: The "masters" of calcium and lipid. Cold Spring Harb Perspect Biol 3: a004556.

Lisman J. 1989. A mechanism for the Hebb and the anti-Hebb processes underlying learning and memory. Proc Natl Acad Sci 86: 9574-9578.

Lu W, Shi Y, Jackson AC, Bjorgan K, During MJ, Sprengel R, Seeburg PH, Nicoll RA. 2009. Subunit composition of synaptic AMPA receptors revealed by a single-cell genetic approach. Neuron 62: 254268.

Lüscher C, Malenka RC. 2012. NMDA receptor-dependent long-term potentiation and long-term depression (LTP/LTD). Cold Spring Harb Perspect Biol 4: a005710.

MacDermott AB, Mayer ML, Westbrook GL, Smith SJ, Barker JL. 1986. NMDA-receptor activation increases cytoplasmic calcium concentration in cultured spinal cord neurones. Nature 321: 519-522.

Magee JC, Johnston D. 1997. A synaptically controlled, associative signal for Hebbian plasticity in hippocampal neurons. Science 275: 209-213.

Magee J, Hoffman D, Colbert C, Johnston D. 1998. Electrical and calcium signaling in dendrites of hippocampal pyramidal neurons. Annu Rev Physiol 60: $327-346$.

Makino H, Malinow R. 2009. AMPA receptor incorporation into synapses during LTP: The role of lateral movement and exocytosis. Neuron 64: $381-390$.

Malinow R, Malenka RC. 2002. AMPA receptor trafficking and synaptic plasticity. Annu Rev Neurosci 25: 103-126.

Malinow R, Schulman H, Tsien RW. 1989. Inhibition of post-synaptic PKC or CaMKII blocks induction but not expression of LTP. Science 245: $862-866$.

Mayer ML. 2006. Glutamate receptors at atomic resolution. Nature 440: 456-462.

Mayer ML, Westbrook GL, Guthrie PB. 1984. Voltage-dependent block by $\mathrm{Mg}^{2+}$ of NMDA responses in spinal cord neurones. Nature 309: $261-263$.
McGee AW, Dakoji SR, Olsen O, Bredt DS, Lim WA, Prehoda KE. 2001. Structure of the SH3-guanylate kinase module from PSD-95 suggests a mechanism for regulated assembly of MAGUK scaffolding proteins. Mol Cell 8: 1291-1301.

Micheva KD, Busse B, Weiler NC, O’Rourke N, Smith SJ. 2010. Singlesynapse analysis of a diverse synapse population: Proteomic imaging methods and markers. Neuron 68: 639-653.

Miller SG, Kennedy MB. 1986. Regulation of brain type $\mathrm{II} \mathrm{Ca}^{2+} /$ calmodulin-dependent protein kinase by autophosphorylation: $\mathrm{A} \mathrm{Ca}^{2+}$-triggered molecular switch. Cell 44: 861-870.

Miller SG, Patton BL, Kennedy MB. 1988. Sequences of autophosphorylation sites in neuronal type II CaM kinase that control $\mathrm{Ca}^{2+}$-independent activity. Neuron 1: 593-604.

Minichiello L. 2009. TrkB signalling pathways in LTP and learning. Nat Rev Neurosci 10: 850-860.

Monyer H, Sprengel R, Schoepfer R, Herb A, Higuchi M, Lomeli H, Burnashev N, Sakmann B, Seeburg PH. 1992. Heteromeric NMDA receptors: Molecular and functional distinction of subtypes. Science 256: $1217-1221$.

Monyer H, Burnashev N, Laurie DJ, Sakmann B, Seeburg PH. 1994. Developmental and regional expression in the rat brain and functional properties of four NMDA receptors. Neuron 12: 529-540.

Mulkey RM, Herron CE, Malenka RC. 1993. An essential role for protein phosphatases in hippocampal long-term depression. Science 261: $1051-1055$

Mulkey RM, Endo S, Shenolikar S, Malenka RC. 1994. Involvement of a calcineurin/inhibitor-1 phosphatase cascade in hippocampal longterm depression. Nature 369: 486-488.

Naisbitt S, Kim E, Tu JC, Xiao B, Sala C, Valtschanoff J, Weinberg RJ, Worley PF, Sheng M. 1999. Shank, a novel family of postsynaptic density proteins that binds to the NMDA receptor/PSD-95/GKAP complex and cortactin. Neuron 23: 569-582.

* Newton AC, Bootman M, Scott JD. 2015. Second messengers. Cold Spring Harb Perspect Biol doi: 10.1101/cshperspect.a005926.

Nowak L, Bregestovski P, Ascher P, Herbet A, Prochiantz A. 1984. Magnesium gates glutamate-activated channels in mouse central neurones. Nature 307: 462-465.

Oh JS, Chen H-J, Rojas-Soto M, Oguni A, Kennedy MB. 2002. Erratum. Neuron 33: 151.

Oh JS, Manzerra P, Kennedy MB. 2004. Regulation of the neuron-specific Ras GTPase activating protein, synGAP, by $\mathrm{Ca}^{2+} /$ calmodulin-dependent protein kinase II. J Biol Chem 279: 17980-17988.

Opazo P, Choquet D. 2011. A three-step model for the synaptic recruitment of AMPA receptors. Mol Cell Neurosci 46: 1-8.

Opazo P, Labrecque S, Tigaret CM, Frouin A, Wiseman PW, De Koninck P, Choquet D. 2010. CaMKII triggers the diffusional trapping of surface AMPARs through phosphorylation of stargazin. Neuron 67: 239252

Patterson MA, Szatmari EM, Yasuda R. 2010. AMPA receptors are exocytosed in stimulated spines and adjacent dendrites in a Ras-ERKdependent manner during long-term potentiation. Proc Natl Acad Sci 107: 15951-15956.

Patton BL, Miller SG, Kennedy MB. 1990. Activation of type II calcium/ calmodulin-dependent protein kinase by $\mathrm{Ca}^{2+} /$ calmodulin is inhibited by autophosphorylation of threonine within the calmodulinbinding domain. J Biol Chem 265: 11204-11212.

Peca J, Feliciano C, Ting JT, Wang W, Wells MF, Venkatraman TN, Lascola CD, Fu Z, Feng G. 2011. Shank3 mutant mice display autistic-like behaviours and striatal dysfunction. Nature 472: 437-442.

Penzes P, Woolfrey KM, Srivastava DP. 2011. Epac2-mediated dendritic spine remodeling: Implications for disease. Mol Cell Neurosci 46: 368 380.

Peters A, Kaiserman-Abramof IR. 1970. The small pyramidal neurons of the cerebral cortex. The perikaryon, dendrites and spines. Am J Anat 127: $321-356$.

Petrini EM, Lu J, Cognet L, Lounis B, Ehlers MD, Choquet D. 2009. Endocytic trafficking and recycling maintain a pool of mobile surface 
M.B. Kennedy

AMPA receptors required for synaptic potentiation. Neuron 63: $92-$ 105.

Rellos P, Pike ACW, Niesen FH, Salah E, Lee WH, von Delft F, Knapp S. 2010. Structure of the CaMKIIS/calmodulin complex reveals the molecular mechanism of CaMKII kinase activation. PLoS Biol 8: e1000426.

Rosenberg OS, Deindl S, Sung RJ, Nairn AC, Kuriyan J. 2005. Structure of the autoinhibited kinase domain of CaMKII and SAXS analysis of the holoenzyme. Cell 123: 849-860.

Rosenberg OS, Deindl S, Comolli LR, Hoelz A, Downing KH, Nairn AC, Kuriyan J. 2006. Oligomerization states of the association domain and the holoenyzme of $\mathrm{Ca} / \mathrm{CaM}$ kinase II. FEBS J 273: 682-694.

Rumbaugh G, Adams JP, Kim JH, Huganir RL. 2006. SynGAP regulates synaptic strength and mitogen-activated protein kinases in cultured neurons. Proc Natl Acad Sci 103: 4344-4351.

Salerno JC, Ray K, Poulos T, Li H, Ghosh DK. 2013. Calmodulin activates neuronal nitric oxide synthase by enabling transitions between conformational states. FEBS Lett 587: 44-47.

Salter MW, Kalia LV. 2004. Src kinases: A hub for NMDA receptor regulation. Nat Rev Neurosci 5: 317-328.

Sans N, Petralia RS, Wang YX, Blahos J, Hell JW, Wenthold RJ. 2000. A developmental change in NMDA receptor-associated proteins at hippocampal synapses. J Neurosci 20: 1260-1271.

* Sassone-Corsi P. 2012. The cyclic AMP pathway. Cold Spring Harb Perspect Biol 4: a011148.

Schworer CM, Colbran RJ, Keefer JR, Soderling TR. 1988. Ca ${ }^{2+} /$ calmodulin-dependent protein kinase II. Identification of a regulatory autophosphorylation site adjacent to the inhibitory and calmodulinbinding domains. J Biol Chem 263: 13486-13489.

Seeburg PH. 1993. The molecular biology of mammalian glutamate receptor channels. Trends Neurosci 16: 359-365.

Sharma RK, Das SB, Lakshmikuttyamma A, Selvakumar P, Shrivastav A. 2006. Regulation of calmodulin-stimulated cyclic nucleotide phosphodiesterase (PDE1): Review. Int J Mol Med 18: 95-105.

Shen K, Meyer T. 1999. Dynamic control of CaMKII translocation and localization in hippocampal neurons by NMDA receptor stimulation. Science 284: 162-166.

Shen K, Teruel MN, Subramanian K, Meyer T. 1998. CaMKII $\beta$ functions as an F-actin targeting module that localizes CaMKII $\alpha / \beta$ heterooligomers to dendritic spines. Neuron 21: 593-606.

Sheng M, Kim E. 2000. The Shank family of scaffold proteins. J Cell Sci 113: $1851-1856$.

Sheng M, Kim E. 2011. The postsynaptic organization of synapses. Cold Spring Harb Perspect Biol 3: a005678.

Shi S, Hayashi Y, Esteban JA, Malinow R. 2001. Subunit-specific rules governing AMPA receptor trafficking to synapses in hippocampal pyramidal neurons. Cell 105: 331-343.

Shi G-X, Han J, Andres DA. 2005. Rin GTPase couples nerve growth factor signaling to $\mathrm{p} 38$ and b-Raf/ERK pathways to promote neuronal differentiation. J Biol Chem 280: 37599-37609.

Shields SM, Ingebritsen TS, Kelly PT. 1985. Identification of protein phosphatase-1 in synaptic junctions: Dephosphorylaton of endogenous calmodulin-dependent kinase II and synapse-enriched phosphoproteins. J Neurosci 5: 3414-3422.

Sik A, Hajos N, Gulacsi A, Mody I, Freund TF. 1998. The absence of a major $\mathrm{Ca}^{2+}$ signaling pathway in GABAergic neurons of the hippocampus. Proc Natl Acad Sci 95: 3245-3250.

Silva AJ, Paylor R, Wehner JM, Tonegawa S. 1992a. Impaired spatial learning in $\alpha$-calcium-calmodulin kinase II mutant mice. Science 257: 206-211.
Silva AJ, Stevens CF, Tonegawa S, Wang Y. 1992b. Deficient hippocampal long-term potentiation in $\alpha$-calcium-calmodulin kinase II mutant mice. Science 257: 201-206.

Sjostrom PJ, Nelson SB. 2002. Spike timing, calcium signals and synaptic plasticity. Curr Opin Neurobiol 12: 305-314.

Spruston N, Schiller Y, Stuart G, Sakmann B. 1995. Activity-dependent action potential invasion and calcium influx into hippocampal CA1 dendrites. Science 268: 297-300.

Steiner P, Higley MJ, Xu W, Czervionke BL, Malenka RC, Sabatini BL. 2008. Destabilization of the postsynaptic density by PSD- 95 serine 73 phosphorylation inhibits spine growth and synaptic plasticity. Neuron 60: $788-802$.

Stork PJ. 2003. Does Rap1 deserve a bad Rap? Trends Biochem Sci 28: 267-275.

Stuart G, Spruston N, Sakmann B, Häusser M. 1997. Action potential initiation and backpropagation in neurons of the mammalian CNS. Trends Neurosci 20: 125-131.

Takeuchi M, Hata Y, Hirao K, Toyoda A, Irie M, Takai Y. 1997. SAPAPs. A family of PSD-95/SAP90-associated proteins localized at postsynaptic density. J Biol Chem 272: 11943-11951.

Tavares GA, Panepucci EH, Brunger AT. 2001. Structural characterization of the intramolecular interaction between the $\mathrm{SH} 3$ and guanylate kinase domains of PSD-95. Mol Cell 8: 1313-1325.

Tolias KF, Bikoff JB, Burette A, Paradis S, Harrar D, Tavazoie S, Weinberg RJ, Greenberg ME. 2005. The Rac1-GEF Tiam1 couples the NMDA receptor to the activity-dependent development of dendritic arbors and spines. Neuron 45: 525-538.

Tomita S, Stein V, Stocker TJ, Nicoll RA, Bredt DS. 2005. Bidirectional synaptic plasticity regulated by phosphorylation of stargazin-like TARPs. Neuron 45: 269-277.

Valtschanoff JG, Weinberg RJ. 2001. Laminar organization of the NMDA receptor complex within the postsynaptic density. JNeurosci 21: 12111217.

Vazquez LE, Chen HJ, Sokolova I, Knuesel I, Kennedy MB. 2004. SynGAP regulates spine formation. J Neurosci 24: 8862-8872.

Walikonis RS, Oguni A, Khorosheva EM, Jeng C-J, Asuncion FJ, Kennedy MB. 2001. Densin-180 forms a ternary complex with the $\alpha$-subunit of CaMKII and $\alpha$-actinin. J Neurosci 21: 423-433.

Wang H, Storm DR. 2003. Calmodulin-regulated adenylyl cyclases: Cross-talk and plasticity in the central nervous system. Mol Pharmacol 63: 463-468.

Yang K, Trepanier C, Sidhu B, Xie YF, Li H, Lei G, Salter MW, Orser BA, Nakazawa T, Yamamoto T, et al. 2012. Metaplasticity gated through differential regulation of GluN2A versus GluN2B receptors by Src family kinases. $E M B O J$ 31: 805-816.

York RD, Yao H, Dillon T, Ellig CL, Eckert SP, McCleskey EW, Stork PJ. 1998. Rap1 mediates sustained MAP kinase activation induced by nerve growth factor. Nature 392: 622-626.

Yoshii A, Constantine-Paton M. 2010. Postsynaptic BDNF-TrkB signaling in synapse maturation, plasticity, and disease. Dev Neurobiol 70: 304-322.

Zeng H, Chattarji S, Barbarosie M, Rondi-Reig L, Philpot BD, Miyakawa T, Bear MF, Tonegawa S. 2001. Forebrain-specific calcineurin knockout selectively impairs bidirectional synaptic plasticity and working/episodic-like memory. Cell 107: 617-629.

Zhu JJ, Qin Y, Zhao M, Van Aelst L, Malinow R. 2002. Ras and Rap control AMPA receptor trafficking during synaptic plasticity. Cell 110: $443-455$. 


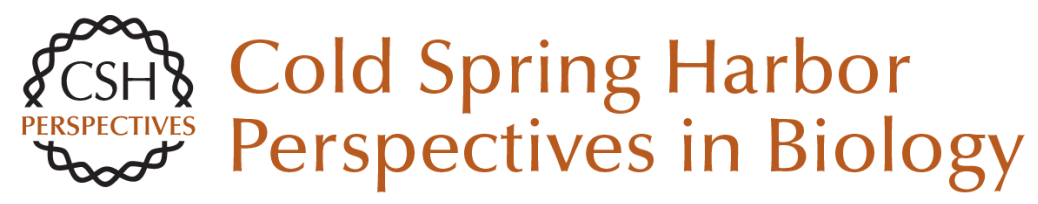

\section{Synaptic Signaling in Learning and Memory}

Mary B. Kennedy

Cold Spring Harb Perspect Biol 2016; doi: 10.1101/cshperspect.a016824 originally published online December 30, 2013

\section{Subject Collection Signal Transduction}

Cell Signaling and Stress Responses Gökhan S. Hotamisligil and Roger J. Davis

Protein Regulation in Signal Transduction Michael J. Lee and Michael B. Yaffe

Synaptic Signaling in Learning and Memory Mary B. Kennedy

Vertebrate Reproduction Sally Kornbluth and Rafael Fissore

Signaling in Lymphocyte Activation Doreen Cantrell

Signaling in Muscle Contraction Ivana Y. Kuo and Barbara E. Ehrlich

Toll-Like Receptor Signaling Kian-Huat Lim and Louis M. Staudt

Signaling Pathways that Regulate Cell Division Nicholas Rhind and Paul Russell
Second Messengers

Alexandra C. Newton, Martin D. Bootman and John D. Scott

Signals and Receptors Carl-Henrik Heldin, Benson Lu, Ron Evans, et al.

Cell Death Signaling Douglas $R$. Green and Fabien Llambi

Signaling Networks that Regulate Cell Migration Peter Devreotes and Alan Rick Horwitz

Signaling Networks: Information Flow, Computation, and Decision Making Evren U. Azeloglu and Ravi lyengar

Signal Transduction: From the Atomic Age to the Post-Genomic Era Jeremy Thorner, Tony Hunter, Lewis C. Cantley, et al.

Signaling by the TGF $\beta$ Superfamily Jeffrey L. Wrana

Subversion of Cell Signaling by Pathogens Neal M. Alto and Kim Orth

For additional articles in this collection, see http://cshperspectives.cshlp.org/cgi/collection/

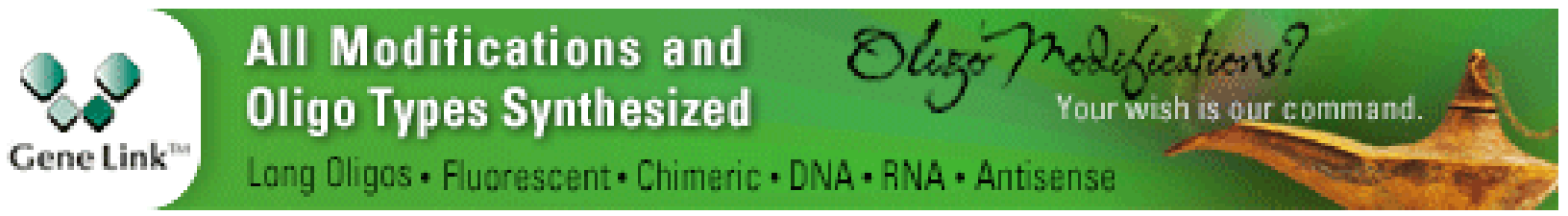

Copyright @ 2016 Cold Spring Harbor Laboratory Press; all rights reserved 